\title{
Dorsolateral Prostate Gland
}

National Cancer Institute

\section{Source}

National Cancer Institute. Dorsolateral Prostate Gland. NCI Thesaurus. Code C77622.

The dorsolateral lobe of the prostate gland in animals. 